\title{
Epidemiological, Clinical and Evolutive Profile of Autosomal Dominant Polycystic Kidney Disease (ADPKD) in Togo
}

\author{
Tsevi Yawovi Mawufemo1*, Amekoudi Eyram Yoan1, Djagadou Kodjo Agbeko², \\ Sabi Kossi Akomola1, Nemi Komi Dzidzonu' ${ }^{2}$, Kodjo Kossi², Tona Komlan Georges', \\ Dolaama Badomta', Attisso Eugene' ${ }^{1}$, Hadabia D'daah'1 ${ }^{1}$ Djibril Mohaman Awalou'
}

\footnotetext{
${ }^{1}$ Department of Nephrology and Hemodialysis of the Sylvanus Olympio University Hospital of Lomé, University of Lome, Lomé, Togo

${ }^{2}$ Internal Medicine Department of the Sylvanus Olympio University Hospital in Lome, University of Lome, Lomé, Togo

Email: *mawufemo.tsevi@gmail.com
}

How to cite this paper: Mawufemo, T.Y., Yoan, A.E., Agbeko, D.K., Akomola, S.K., Dzidzonu, N.K., Kossi, K., Georges, T.K., Badomta, D., Eugene, A., D'daah, H. and Awalou, D.M. (2018) Epidemiological, Clinical and Evolutive Profile of Autosomal Dominant Polycystic Kidney Disease (ADPKD) in Togo. Open Journal of Nephrology, 8, 117-123.

https://doi.org/10.4236/ojneph.2018.84013

Received: November 19, 2018

Accepted: December 26, 2018

Published: December 29, 2018

Copyright (๑) 2018 by authors and Scientific Research Publishing Inc.

This work is licensed under the Creative

Commons Attribution International

License (CC BY 4.0).

http://creativecommons.org/licenses/by/4.0/

\begin{abstract}
Objective: To describe the epidemiological, clinical and evolutionary profile of ADPKD in Togo. Methods: A retrospective descriptive transversal study over a period of 8 years (2011-2018) which focused on the analysis of patients' records diagnosed with ADPKD. The diagnosis of ADPKD was retained on the basis of the ultrasound criteria of PEI. Results: During the study period, 27 patients had polycystic kidney disease with a prevalence of $0.87 \%$. The average age was $51.6 \pm$ 16.4 years. There were 10 men (37\%) and 17 women (63\%), a sex ratio (M/F) of 0.58 . The concept of family cystic kidney disease was found in $6(22.2 \%)$ patients. The clinical presentations were dominated by arterial high blood pressure, abdominal pain and abdominal mass respectively in $77 \%, 63 \%$ and $63 \%$ of cases. Five patients (18.5\%) had a glomerular filtration rate (GFR) greater than $90 \mathrm{ml} / \mathrm{min}, 17(62.9 \%)$ had a GFR $<60 \mathrm{ml} / \mathrm{min}$. All patients $(100 \%)$ had multiple renal cysts, 16 patients (59.3\%) had dedifferentiated kidneys. Six patients (22.2\%) had liver cysts, one patient (3.7\%) had lithiasis. Genetic was not achieved because of the poor technical platform and the high cost of these tests. Conclusion: ADPKD is common in our department. It appears to be associated with a high rate of chronic renal failure.
\end{abstract}

\section{Keywords}

Polycystic Kidney Disease, CKD, Togo

\section{Introduction}

ADPKD is a chronic multi-systemic disease of hereditary origin, characterized 
by the development of cysts in both kidneys as well as by variable extrarenal organ manifestations [1]. It affects one birth in 800 or 4 to 6 million people around the world [2]. This is an autosomal dominant inheritance disorder. Therefore, the father or mother of the patient with ADPKD also carries the disease. Autosomal dominant inheritance implies that members of the same family are affected in each generation, with the risk of transmitting the disease from the affected parent to the child at 50\%, regardless of gender. ADPKD is caused by mutations in the PKD1 gene (located on chromosome 16p13.3) or PKD2 (chromosome 4q21) [1].

In Togo, ADPKD is relatively common in hospitals. Our study is the first in Togo. At the time of the development of various therapies more or less effective on the ADPKD [3], it seemed important TOUS to describe the epidemiological, clinical and evolutive profile of the ADPKD patients of our hospital population.

\section{Patients and Method}

Our study was conducted in the nephrology and hemodialysis department of the Sylvanus Olympio University Hospital of Lomé in Togo. This department, which is the only public center for the treatment of kidney diseases in the country, also carries out care and research activities. This is a retrospective cross-sectional descriptive study from January 1st, 2010 to December 2017, which is an 8-year period that focused on the analysis of patients with ADPKD diagnosed cases. The diagnosis of ADPKD was retained on the basis of the ultrasound criteria of PEI [4]. The kidneys were considered dedifferentiated if the renal cortex appeared hypoechogenic relative to the medulla. Included, were all patients aged 15 years and more who are being followed-up at the Sylvanus Olympio University Hospital in Lomé for ADPKD. Patients who did not meet the PEI ultrasound criteria and patients under 15 years of age were not included. The concept of family cystic kidney disease has also been investigated in the interrogation of patients diagnosed with ADPKD. The clearance of serum creatinine has been estimated using the Modification Diet of Renal Disease (MDRD) formula [5]. Patient data were collected using charts with socio-demographic, clinical, biological and ultrasound parameters. This data was analyzed and processed using Sphinx Plus software (Lexica), version 5.1.0.3.

Definition of PEI criteria: The presence of three or more (unilateral or bilateral) renal cysts is sufficient for establishing the diagnosis in individuals aged 15 to 39 years, two or more cysts in each kidney is sufficient for individuals aged 40 to 59 years, and four or more cysts in each kidney is required for individuals $\geq 60$ years. Conversely, fewer than two renal cysts in at-risk individuals aged $\geq 40$ years are sufficient to exclude the disease.

\section{Results}

During the study period (2010-2017), 3064 patients were received in the Department of Nephrology and hemodialysis of the Sylvanus Olympio University Hos- 
pital of Lomé. Twenty-seven patients had polycystic kidney disease with a prevalence of $0.87 \%$. Among the 27 patients, there were 10 men (37\%) and 17 women (63\%) a sex ratio of 0.58 . Table 1 showed the sociodemographic characteristicaspect. The concept of family cystickidney disease was found in 6 (22.2\%) patients. The average age was 51.6 years \pm 16.4 years with extremes of 25 and 91 years. One patient (3.7\%) was carrying Human Immunodeficiency Virus (HIV), two (7.4\%) were sickle cell. The genetic study was not performed.

\subsection{Clinical Manifestation}

The clinical presentations were dominated by high blood pressure, abdominal pain and abdominal mass respectively in $77 \%, 63 \%$ and $63 \%$ of cases. Table 2 shows the distribution of patients according to the clinical manifestations of polycystic. Four patients (14.8\%) had electrocardiographic left ventricular hypertrophy. Three patients (11.1\%) had died.

\subsection{Biological Parameters}

The mean hemoglobin level was $10.6 \mathrm{~g} / \mathrm{dl} \pm 2.6 \mathrm{~g} / \mathrm{dl}$ with extremes of 5.7 and $14.2 \mathrm{~g} / \mathrm{dl}$.

The mean serum calcium was $88.4 \mathrm{mg} / \mathrm{L} \pm 11.9 \mathrm{mg} / \mathrm{L}$ with extremes of 60 and $124 \mathrm{mg} / \mathrm{l}$. The mean proteinuria of $24 \mathrm{~h}$ was $501 \mathrm{mg} /$ day $\pm 458 \mathrm{mg} /$ day with extremes of 84 and $2 \mathrm{~g} /$ day. Five patients (18.5\%) had a glomerular filtration rate (GFR) greater than $90 \mathrm{ml} / \mathrm{min}$, two patients $(7.4 \%$ ) had a GFR $<15 \mathrm{ml} / \mathrm{min}$ but not yet in hemodialysis and five patients (18.5\%) were in iterative hemodialysis at two sessions per week. Table 3 shows the distribution of patients according to creatinine clearance.

\subsection{Echographic Parameters}

The diagnosis of polycystic kidney disease is based on clinical arguments, the notion of family cystic kidney disease and especially on the ultrasound arguments of the disease. All patients (100\%) had multiple kidney cysts, 16 patients (59.3\%) had dedifferentiated kidneys. Table 4, Table 5 shows the distribution of

Table 1. Sociodemographic and clinical characteristics of the patients.

\begin{tabular}{|c|c|c|}
\hline & Effective & $\%$ \\
\hline \multicolumn{3}{|l|}{ Sex } \\
\hline Male & 10 & $37 \%$ \\
\hline Female & 17 & 63 \\
\hline \multicolumn{3}{|l|}{ Profession } \\
\hline Actives & 22 & 81.4 \\
\hline Pensionners & 4 & 14.8 \\
\hline Student & 1 & 3.7 \\
\hline \multicolumn{3}{|c|}{ Comorbidities } \\
\hline HIV & 1 & 3.7 \\
\hline Sickle cell & 2 & 7.4 \\
\hline
\end{tabular}


Table 2. Division of patients according to clinical manifestations.

\begin{tabular}{ccc}
\hline & Effective & $\%$ \\
\hline Abdominal pain & 17 & 63.0 \\
HBP & 21 & 77.8 \\
Macroscopic hematuria & 6 & 22.2 \\
Urinary infection & 7 & 25.9 \\
Abdominal mass & 17 & 63.0 \\
\hline
\end{tabular}

HBP: High Blood Pressure.

Table 3. Patient Division Based on Creatinine Clearance (MDRD).

\begin{tabular}{ccc}
\hline & Effective & $\%$ \\
$90>$ GFR $\geq 60$ & 5 & 18.5 \\
$60>$ GFR $\geq 30$ & 5 & 18.5 \\
$30>$ GFR $\geq 15$ & 5 & 18.5 \\
GFR $<15$ (waiting for dialysis) & 5 & 18.5 \\
GFR $<15$ (dialysis) & 2 & 7.4 \\
Total & 5 & 18.5 \\
\hline
\end{tabular}

GFR: Glomerular Filtration Rate.

Table 4. Division of patients according to ultrasound parameters of polycystic kidney disease.

\begin{tabular}{ccc}
\hline & Effective & $\%$ \\
\hline Multiple renal cyst & 27 & 100 \\
Dedifferentiated kidneys & 16 & 59.3 \\
Liver cyst & 6 & 22.2 \\
Pancreatic cyst & 0 & 0.0 \\
Splenic cyst & 0 & 0.0 \\
Renal lithiasis & 1 & 3.7 \\
\hline
\end{tabular}

Table 5. Division of patients according to the circumstances of discovery.

\begin{tabular}{ccc}
\hline & Effective & $\%$ \\
\hline Adventitious & 4 & 14.8 \\
CKD & 10 & 37.0 \\
Lumbar-abdominal pain & 8 & 29.6 \\
Other: hematuria, urinary system infections & 5 & 18.5 \\
Total & 27 & 100 \\
\hline
\end{tabular}

patients according to the ultrasound parameters of polycystic kidney disease. Six patients $(22.2 \%)$ had liver cysts, one patient (3.7\%) had renal lithiasis. None of 
our patients had splenic or pancreatic cysts.

\subsection{Evolution}

In our series, 3 patients (11.1\%) had died two of whom had infectious complications and one a stroke. The mean follow-up time for deceased patients was 2.6 years. The two patients who died of infectious cause were 44 years old and 45 years old. The one who died of a stroke was 50 years old.

\section{Discussion}

ADPKD is a hereditary disease that, because of its autosomal dominant inheritance, affects about half of the family members. In our series the notion of family cystic kidney disease was found in 6 (22.2\%) of our patients. BOURQUIA et al. [6] reported that the family survey allowed early diagnosis of ADPKD. The diagnosis of mutation remains resolutely the responsibility of genetics. In our current practice this analysis is not carried out because of the lack of adapted material and also because of the high cost of these tests.

The average age of our patients was $51.6 \pm 16.4$ years. RAQUI et al. [7] reported an average age of $48.8 \pm 16.6$ years; N'GUESSAN in 2015 in Côte d'Ivoire [8] had observed in his patients, an average age of $47.5 \pm 13.8$ years. We observed a sex ratio of 0.8. N'GUESSAN et al. [8] in their series reported a sex ratio of 1 . Similarly in Senegal, out of 55 subjects with PKD, 57\% were men [9]. It appears that there is no real predominance of sex.

ADPKD is a serious condition because of its multiple complications, which most often represent the reason for consultation and the circumstances of discovery. In this study the reasons for consultation were dominated by kidney failure (37\%), and lower back pain (29.6\%), while in Senegal [9] the most common circumstances of discovery were lower backpain (52.2\%) and high blood pressure (17.4\%). The most common clinical manifestation in our series was high blood pressure (77\% of cases). High blood pressure is the most common complication of ADPKD. It was found in 56\% of cases in the N'GUESSAN series [8] and in 36\% of cases in Senegal [9]. This high blood pressure appears early, already when the GFR is still greater than $75 \mathrm{ml} / \mathrm{min}$, compared to the general population [10]. This observed difference can be explained by the fact that high blood pressure is more common in kidney failure, especially when the patient has a family history of high blood pressure. High blood pressure during ADPKD is associated with increased renal volume [1]. Serra et al. [1] were able to show that in patients with ADPKD, aged 15 to 49 years, with a GFR greater than 60 $\mathrm{ml} / \mathrm{min} / 1.73 \mathrm{~m}^{2}$, who, takes ACE inhibitors, were within a target blood pressure range of $95 / 60$ to $110 / 75 \mathrm{~mm} \cdot \mathrm{Hg}$, the increase in renal volume was slower [1].

CKD during ADPKD is very common since about 17 patients $(62.9 \%)$ in our series had a CKD and among them two (7.4\%) had an ESRD but not yet on hemodialysis and five patients (18.5\%) an ESRD in iterative hemodialysis. The proportion of polycystic hemodialysis patients in our departement was $6.1 \%$, 
whereas it is generally around $10 \%$ [11]. This work complements polycystic kidney disease in Africa. Although there is no consensus in the diagnosis, monitoring and treatment of this pathology [11], some new therapies have emerged. In our present work we have not addressed the therapeutic aspect of polycystic kidney disease.

In Benin, AGBOTON et al. [12] in their series noted that $75 \%$ of patients had stage III chronic kidney disease (CKD). EL HADJ FARY KA in Senegal noted that $51 \%$ of patients were CKD, the majority being in stage $\mathrm{I}$, followed by dialysis [13]. These very high rates of CKD can be explained by the late use of patients for care because of their ignorance of the disease but also because of very poor socio-economic conditions. Indeed, the guaranteed minimum inter-professional salary being $58 €$ (SMIG $=38,000$ FCFA), taking care of oneself is a real problem for patients in Togo. It should also be noted that the absence of universal health insurance contributes enormously to the lack of health care.

Six patients $(22.2 \%)$ in our series had macroscopic hematuria. Hematuria is very common during $A D P K D$ and occurs at least once in life in half of patients. Although it is often a source of great concern, it is usually benign. More rarely, it is due to an infection of the urinary system. As far as urinary infections are concerned, the danger is that, from there, the infection can spread to the kidney itself. There is a risk that a cystic kidney infection treated too late or insufficiently renders a nephrectomy essential, thus greatly reducing renal function [1].

ADPKD is characterized by the slow and progressive appearance of cysts mainly in the kidneys. It can be associated with the development of cysts in the liver, spleen and pancreas. Extrarenal manifestations in our study were mainly dominated by liver cysts (22.2\%). GOMEZ et al. observed in their study that the most frequent extra-renal manifestations were liver cysts (62\%) and pancreatic cysts (9\%) [14]. This observed difference can be explained by the quality of the ultrasound scan used.

In this study, 3 patients $(11,1 \%)$ had died including 2 infectious complications and 1 stroke. In fact the prevalence of intracranial aneurysms is about $10 \%$ (compared to $2 \%-3 \%$ in the general population) [1]. The incidence of cerebral bleeding associated with aneurysms, however, is low. A general screening is not recommended by most experts and is reserved for special situations, for example to pilots, before a planned transplant, or to families with frequent aneurysms.

\section{Conclusion}

ADPKD is common in our department. It appears to be associated with a high rate of chronic renal failure. Systematic screening of the affected family members should be encouraged for early referral of patients to nephrologists to provide comprehensive and long-term care for patients and relatives.

\section{Conflicts of Interest}

The authors declare no conflicts of interest regarding the publication of this paper. 


\section{References}

[1] Serra, A.L., Puhan, M.A. and Rüfenacht, D. (2017) PKRAD: Polykystose rénale autosomique dominante. Forum méDical Suisse, 17, 330-335.

https://doi.org/10.4414/fms.2017.02919

[2] Burtey, S. and Berland, Y. (2009) La Polykystose rénale. La Rev Prat, 59, 837-838.

[3] Serra, A.L., Poster, D., Kistler, A.D., Krauer, F., Raina, S., Young, J., et al. (2010) Sirolimus and Kidney Growth in Autosomal Dominant Polycystic Kidney Disease. New England Journal of Medicine, 363, 820-829. https://doi.org/10.1056/NEJMoa0907419

[4] Pei, Y., Magistroni, R., Parfrey, P., Coto, E., Torra, R., San Millan, J.L., et al. (2009) Unified Ultrasonographic Diagnostic Criteria for Autosomal Dominant Polycystic Kidney Disease. Journal of American Society of Nephrology, 20, 205-212. https://doi.org/10.1681/ASN.2008050507

[5] National-Kidney-Foundation (2002) K/DOQI Clinical Practice Guidelines for Chronic Kidney Disease: Evaluation, Classification, and Stratification. Am J Kidney Dis., 39, S1-266.

[6] Bourquia, A. (2002) La maladie polykystique autosomique dominante au Maroc: Enquête multicentrique à propos de 308 familles. Néphrologie, 23, 93-96.

[7] Raqui, A., Berrada, S., Elhoussni, S., et al. (2015) Facteurs de progression de la polykystose rénale autosomique dominante (ADPKD): À propos de 283 cas. Néphrologie \& Thérapeutique, 11, 389. https://doi.org/10.1016/j.nephro.2015.07.377

[8] Ackoundou-N'guessan, C., Lagou, D.A., Loukou, K., et al. (2015) L'insuffisance rénale chronique au cours de la polykystose rénale autosomique dominante en Afrique noire: Etude retrospective observationelle. Rev Int sc Méd, 17, 145-151.

[9] Diouf, B., Dia, D. and Ka, M.M. (1998) Autosomal Dominant Polycystic Kidney Disease in the Hospital Milieu in Dakar (Senegal). Dakar Med, 43, 205-208.

[10] Schrier, R.W., McFann, K.K. and Johnson, A.M. (2003) Epidemiological Study of Kidney Survival in Autosomal Dominant Polycystic Kideny Disease. Kidney International, 63, 768-785. https://doi.org/10.1046/j.1523-1755.2003.00776.x

[11] Chapman, A.B., Devuyst, O., Eckardt, K.U., et al. (2015) Autosomal-Dominant Polycystic Kidney Disease (ADPKD): Executive Summary from a Kidney Disease: Improving Global Outcomes (KDIGO) Controversies Conference. Kidney International, 88, 17-27. https://doi.org/10.1038/ki.2015.59

[12] Agboton, B.L., Vigan, J., Azonbakin, S., et al. (2015) Polykystose renale autosomique dominante (ADPKD) au CNHU-HKM de Cotonou: Profil épidémiologique, clinique, biologique et intérêt du dépistage familial. Pan African Medical Journal, 22, 203. https://doi.org/10.11604/pamj.2015.22.203.7678

[13] Ka, E.F., Seck, M., Niang, A., Cisse, M. and Diouf, B. (2010) Pattern of Autosomal Dominant Polycistic Kidney Diseases in Black Africans. Saudi Journal of Kidney Diseases and Transplantation, 21, 81-86.

[14] Gomez, F.P., Cosmesg, P., Becerra, C.L. and Romo, T.J. (2010) Análisis clínico de una población con poliquistosis renal autosómica dominante. Nefrología, 30, 87-94. 